cleansed with a corrosive sublimate lotion and an antiseptic dressing applied, which was retained in position by a broad bandage placed round the chest. After a few days the left chest was strapped in place of the bandage. The progress of the case towards recovery was practically uneventful. More or less pain was felt in the neighbourhood of the wound for several weeks. There was very little cough and scarcely any expectoration. The temperature remained above the normal for nearly a month, and reached $103.6^{\circ} \mathrm{F}$. The breath sounds showed a marked improvement during the first week, but after that time progress was not so rapid. The râles gradually disappeared as the effused blood was absorbed. The patient was at first allowed cool drinks freely, and ice to suck. A quarier of a grain of morphia was given hypodermically twice daily for a fortnight, and then every nigbt for ten days longer. When the temperature rose above $101^{\circ}$ he was given three grains of quinine in powder twice daily, and later, owing to a marked specific history, he was ordered a mixture of bark, with perchloride of mercury and iodide of potassium Abont a fortnight after the accident $I$ was interested to find a marked ecchymosis about the angles of the lower ribs, which extended down towards the loins. This sign was regarded by Valentine as pathognomonic of blood effused within the chest, and. is mentioned in Guthrie's Commentaries. It was, as he says, "very dissimilar to that which occurs af ter a blow or wound, and which takes place shortly after an accident, being aronnd the wound if there be one, and extending from it. The patient also complains of pain when the bruised part is pressed by the fingers, and these characters are not observed in the ecchymosis, the sign of effasion. Its colour is identical with that which appears on the abdomen of persons some time after death, a bright violet (violet très-éclainci) appears about ten days after the receipt of the injury, sometimes later." I last saw the patient on May 18th. Both wounds were then soundly healed, the breath sounds were scarcely as free over the base of the left lung, as over the right. No râles could be heard, but there was some increased resistance on percussion. He was able to get about well.

Sherringham, Norfolk.

\section{A CASE FOR DIAGNOSIS.}

By Raymusd H. Phillmmore, N.D.

I ATRENDED a case last year which presented so many curious features that $I$ think it may be of suffient interest to lay before the readers of THE L.INCET. Briefly, the history of the case was as follows.

On Feb. 29th, 1896, I was summoned to attend a man, aged nineteen years. He was a total abstainer, with a family history of phthisis. He complained of pain in the right side, vomiting, rigors, and constipation. He suffered from a most intense and persistent frontal headache. He said that he had not been feeling well for ten days or a fortnight. Physical examination disclosed a liver greatly enlarged. It extended from the lower border of the fifth rib to nearly the level of the umbilicus in the middle line and below that level in the right flank. It also extended three or four inches to the left of the middle line. The organ was very sensitive on palpation. The spleen was also enlarged. A herpetic eraption was present round the lips. The heart and lungs were normal. The temperature was $101.4^{\circ} \mathrm{F}$., the pulse was 94 , and the respiration was 20 per minute. On March 1st there occurred violent epistaxis with severe headache. On the 2nd the paitient had two chills; the headache was unrelieved by ordinary treatment. The temperature was $101.5^{\circ}$ in the morning, but it became normal in the evening. On the $3 \mathrm{rd}$ a few suspicious spots were observed on the abdomen. The temperature in the morning was $99^{\circ}$ and in the evening $100 \cdot 8^{\circ}$. On the 4th four rigors occurred. The tongue was dry, brown, and fissured. The temperature in the morning and evening was normal. On the 5 th there was epistaxis. On the 6 th pronounced jaundice was present. Two stools were passed. The temperature in the morning was $103.6^{\circ}$, but in the evening it was normal. On the 7 th epistaxis occurred. On the 8th the patient suffered from distressing rigors with a flushed face, followed by profuse perspiration simulating a malarial attask. In the morning the temperature were $100^{\circ}$ and in the evening it was $99.8^{\circ}$. On the 9th and 10th there were rigors. On the 11th the patient again suffered from rigors. He passed three stools on this date. On the 12 th and 13th rigors again occurred. The abdomen was tympanitic. On the 14th there were hiccough, vomiting of bile, and enlargement of the superficial thoracic veins on the right side. The rigors were followed, as before, by profuse perspiration. The patient was continually drowsy. The conjunctivæ were greenish-yellow in colour. He complained of severe pain in the right side. Albumin was present in the urive, but not in excessive quantity. Delirium supervened. The morning and evening temperatures were $100^{\circ}$ and $100.4^{\circ}$ respectively. On the 15th at 9 A.M. the temperature was $107^{\circ}$, the respiration was 28 per minute, and the pulse was 116. The patient was delirious. The heart's action was feeble and intermittent. Hiccough was present. At 3 P.M. the temperature was normal ; there was vomiting. At 7 P.M. the temperature was 102 and the respiration was 5 per minute. On the 16th, 17th, and 18th persistent chills occurred and there was rapid emaciation. On the 19th an attack of epistaxis occurred, with stertorons breathing (18 per minute); he was very restless and vomited. The morning and evening temperatures were $104^{\circ}$ and $102^{\circ}$ respectively. On the 20th at 9 A.M. the temperature was $99.5^{\circ}$, the pulse was 110 , and the respiration was 18 , and at 5 P.M. they were $101^{\circ}, 132$, and 28 respectively. At 7 P.M. sudden collapse and death occurred.

Was this a case of hypertrophic cirrhosis of the liver complicated with typhuid fever of an atypical form? The sudden collapse might then be attributed to perforation of the bowel with emptying of contents into the peritoneal cavity. Unfortunately no post-mortem examination was allowed. I may add that the patient received the attention of a regular hospital nurse.

Cookshire, Quebec, Canada.

\section{AVULSION OF THE UTERUS.}

By E. Hickson SMITH, M.R.C.S. ENG., L.R.C.P. LoND., ASSISTANT SURGEON TO THE LONGTON HOSPITAL.

ON the morning of Dec. $29 \mathrm{th}, 1896$, I was sent for in haste to go five miles into the country to see a patient who had just been confined. On my arrival at the house the midwife informed me that the child had been born two hours previously on the foor while the mother was on her hands and knees. After separating the child and getting the patient into bed she found a large lump protruding from the vagina, whioh she thought was the head of another child, and consequently pulled on it for three-quarters of an hour until she had dragged it away. I immediately examined this, and found it to be the inverted uterus. This I turned back again, and found it was the whole of the uterus and cervix, with its peritoneal covering, and one broad ligament and Fallopian tube, without the ovary. The broad ligament of the other side was congenitally absent. On examining the patient I perceived her to be suffering from shock. $\mathrm{Oa}$ inserting my finger into the vagina, it moved freely about among the intestines, and the absence of the uteras and cervix was distinctly apparent. The bæmorrhage was but slight, and gave no trouble. I feared that the natural result of such a catastrophe would be prolapse of the bowels and general peritonitis. I therefore kept the patient on her back, put in an antiseptic plug, and in order to quiet the peritoneum administered morphia, and ordered a strictly milk diet. Contrary to what might have been expected no serious symptoms occurred. The peritoneum closed up and the top of the vagina cicatrised over. In about three weeks the patient was able to get up and go about. On visiting her three months later she was in her usual health and the vagina was then a $c u l \cdot d e-s a c$. I am sure that many members of the medical profession will be interested to hear of this remarkable case and recovery.

Longton, Staffordshire.

Presentations to Medical Men.-Dr. Robert Fullerton, surgeon to the Throat Department of the Greenock Infirmary, has been presented with a solid silver tray by the staff of the hospital as a tolen of esteem.- Surgeon-Captain Forrest, of the 3rd Lanark Rifle Volunteers, has been presented with a handsome surgical case by the members of hia ambulance class. 